\title{
Identidad/es. Una reflexión sobre las identidades de la mujer en el cine de Icíar Bollaín y Gracia Querejeta
}

\author{
Identity / identities. A reflection on the identities of women in \\ film by Iciar Bollaín and Gracia Querejeta
}

CARMEN ORS MARQUÉS*

\begin{abstract}
Resumen: Valiéndome de un ya consolidado género filosófico que utiliza el cine para rastrear, reflexionar e ilustrar los problemas filosóficos, me propongo analizar dos de las películas clave del cine contemporáneo realizado por mujeres en España. Concretamente Te doy mis ojos (2003) de Icíar Bollaín, por una parte, y Siete mesas de Billar Francés (2007) de Gracia Querejeta. El espinoso tema que estas películas permiten ilustrar, a mi modo de ver, es el tema de la identidad humana y en especial el de la identidad de la mujer. Tanto el uno como el otro han sido objeto de fecundas controversias en la tradición epistemológica moderna y en la historia del feminismo. Asomándome siquiera al abismo que supone este problema, pretendo utilizar ambos films para mostrar en primer lugar la impronta de lo irracional como fuente de identidad y para convenir con una de las enseñanzas que considero nos ha legado el feminismo: la importancia de desvincularse de los modelos hegemónicos y monolíticos de identidad, para así comprender (parafraseando a Carla Lonzi) que la identidad pasa por un triple movimiento: toma de conciencia, deseo de ser libre y voluntad de existir.

Palabras clave: cine, identidad, trascendencia, inmanencia, irracionalismo, narración, Simon de Beauvoir, Carla Lonzi, feminismo.
\end{abstract}

\begin{abstract}
Using an already established philosophical genre that deals with film as a tool to track, reflect and illustrate philosophical problems, I will analyze two of the key films made by women in Spain. Specifically Te doy mis ojos (2003) Icíar Bollaín and Siete mesas de billar francés (2007) Gracia Querejeta. The thorny issue these films illustrate, it's, in my view the subject of human identity and especially the identity of the woman. Both, the one and the other have been fruitful controversies in modern epistemological tradition and in the history of feminism. Peering into the abyss even posed this problem, I intend to use both films to show first the imprint of the irrational as a source of identity and to agree with one of the lessons that I believe feminism has bequeathed us. A teaching that prevent us from hegemonic and monolithic models of identity, to make us understand (Carla Lonzi paraphrasing) that identity goes through a triple movement: awareness, desire to be free and will to exist.
\end{abstract}

Keywords: film, identity, transcendence, immanence, irrationalism, Gellner, Simon de Beauvoir, Carla Lonzi, feminism.

Fecha de recepción: 07/06/2016. Fecha de aceptación: 27/07/2016.

* Profesora de educación Secundaria del IES Barri del Carme, Valencia, ha realizado su tesis doctoral sobre Ernest Gellner. Líneas de investigación: tradición epistemológica moderna, nacionalismo y modernidad, filosofía y cine. Publicaciones recientes: ORS, C., SANFELIX, V., (2013): “Por qué luchamos? La antropología política del documental norteamericano de propaganda bélica.”, Eikasía, Revista de Filosofía; ORS, C., SANFELIX, V., (2014): "Esprit détaché. El yo en las meditaciones", Valencia, Pre-Textos. 
El problema de la identidad personal ha sido uno de los tópicos más relevantes y peliagudos de la tradición epistemológica moderna. El propósito de esta modesta reflexión a partir del cine es señalar uno de los errores en los que a mi juicio cayó está tradición. La tradición epistemológica llevó a cabo un tratamiento de la naturaleza humana y de la identidad personal a histórico y universal, olvidándose del cuerpo y de su significación sexual. En aras de la concreción, como he señalado, voy a tratar este tema tan abstracto realizando un comentario filosófico de dos películas españolas.

En cierta manera podría entenderse que lo que me planteo es una sección particular del capítulo general del problema filosófico de la identidad personal. Pero, como veremos, reflexionando sobre lo particular quizás podamos llegar a arrojar alguna luz sobre lo universal.

Lo particular, pues, es en este caso la mirada que dos directoras de cine españolas nos ofrecen sobre la mujer en dos de sus películas: Te doy mis ojos, de Icíar Bollaín, y Siete mesas de billar francés, de Gracia Querejeta. Ambas planean sobre la problemática de las relaciones personales: los roles, los equilibrios de poder, las expectativas, lo que se ve y lo que se oculta en ellas... aunque se difieran en el dramatismo de la perspectiva elegida, pues mientras Querejeta nos cuenta una historia dura, sí, pero no extrema; Bollaín, como es bien sabido, pone su foco sobre esa situación límite que constituye la violencia de género.

Aunque los dos films son muy diferentes creo que permiten ser leídos desde un tema común que cabría enunciar como el de la identidad conquistada. Y es que Pilar y Ángela, las protagonistas de ambas historias, consiguen algo así como conquistar una nueva identidad, después de enfrentarse a un proceso tremendamente traumático, en el caso de Pilar (victima de la violencia de su marido), y doloroso, de otra forma, en el caso de Ángela. Pero ¿por qué hablo de "conquistar" la identidad?, ¿qué implicaciones supone este proceso?, ¿cuál el statu quo ante que sugiero que hay que superar?

Ya he advertido que el problema de la identidad personal es uno de los temas, como podríamos decir inspirándonos en Hume, más laberínticos de la filosofía. En general, es un problema que se ha abordado desde ópticas epistemológicas y ontológicas, sumamente abstractas. Lo que el feminismo, al reflexionar sobre esta cuestión, puede añadir -y de hecho ya ha añadido- al tratamiento de la misma es un bajarla del cielo de la especulación al terreno concreto de la historia y la sociedad, ya que necesariamente su punto de partida no es un yo desvinculado -por tomarle prestada ahora la expresión a Charles Taylor (1997); o, mejor aún, a Sheila Benhabib (1995) - sino un yo esencialmente caracterizado por un cuerpo dotado de significación sexual y, por ello mismo, de género (Najera, 1999).

Y es que resulta evidente que si la tradición feminista ha abordado el tema de la identidad de la mujer no lo ha hecho simplemente por razones teóricas, ontológicas y epistemológicas sin más, sino respondiendo a un interés práctico: la emancipación. Saber qué o quién soy, y qué elementos conforman mi identidad, para que ésta sea no un destino sino una opción. O en términos beauvoirianos: la condición para alcanzar la trascendencia. Pues, aun reconociendo que el movimiento feminista es plural y que en su seno acoge múltiples tradiciones, seguiría suscribiendo yo las quasi-panfletarias palabras de Carla Lonzi a modo de lema que le daría su unidad: "Toma de conciencia, deseo de ser libre y voluntad de existir" (Lonzi, 1991). 
Vayamos pues, sin más dilación, a ver qué podemos aprender de general a partir del caso particular de la historia de estas mujeres cuyas vidas nos presentan los films de Bollaín y Querejeta.

La primera enseñanza es clara. Pilar y Ángela, las respectivas protagonistas de los mismos, han llegado a ser las mujeres que son, esposas y madres, en el contexto de un horizonte social proporcionado por un tiempo y un lugar concreto: la España del último cambio de siglo. Ello supone tener que cargar sobre sí con un conjunto de apreciaciones de sentido instauradas histórica, social y culturalmente, son en terminología de Beauvoir sujetos situados.

Pero habría que añadir y subrayar que esas instituciones o estructuras, a través de las cuales se les imponen las categorías que constituyen la identidad de la que parten, no son monolíticas sino plurales incluso en el seno de esa misma sociedad, pues en ambas películas, aparte de las protagonistas, aparecen otros personajes femeninos cuya manera de ser en el mundo -por servirnos ahora del utillaje conceptual heideggeriano- es bien diferente al de ellas mismas: la hermana de Pilar, su madre o sus compañeras de trabajo en la película de Bollaín; y del mismo modo Charo, la socia de Ángela, y su madre, o la empleada costarricense de ambas, Evelyn, en la película de Querejeta.

Y si existen esas diferentes maneras de ser mujer que se muestran en las películas dialécticamente, o literalmente en los diálogos que los personajes mantienen entre sí, es porque los procesos de socialización que les han llevado a encarnar un conjunto de significados no determinan la historia de la vida de una persona. Y esta es la segunda enseñanza general que podemos sacar. Los contextos sociales, culturales e históricos condicionan, a veces de una manera extraordinariamente severa, los horizontes de sentido contra cuyo trasfondo se construye la identidad de una persona, pero no determinan esta, pues lo que define a una persona es la capacidad, por remota que sea, de trascenderlos.

Podríamos utilizar estas enseñanzas para calibrar lo que de acertado puede haber en algunas de las posiciones más abstractas sobre la identidad personal a las que antes aludíamos. Pensemos, por ejemplo, en la tradición cartesiana. La misma se caracteriza por considerar al yo como un alma trascendente, desencarnada. También como una sustancia o cosa. Pero lo que Ángela y Pilar vienen a recordarnos es que ahí, en esa posición ontológica aparentemente inocua, se están obviando las dos conclusiones que acabamos de sacar. El yo siempre está situado en un determinado espacio ético -queremos decir: de costumbres-, por lo tanto social; y hasta el momento al menos, en todas las sociedades conocidas, el locus que corresponde a cada yo en ese espacio está condicionado por su sexo (también, claro está, por otras circunstancias como la clase social a la que se pertenece). Por otra parte, el yo no es una cosa. Las cosas están, en tanto que tales, sometidas a leyes naturales. Las personas, en tanto que personas, sometidas a leyes... sociales o culturales. Por lo tanto, históricamente devenidas. Por lo tanto, políticamente transformables.

Habría que ser justos, no obstante, con Descartes, y no perder de vista el sentido emancipatorio que tenía su duda; al fin y al cabo, una concreción metódica de aquel examen de la propia vida en el que Sócrates ${ }^{1}$ cifraba el valor de la misma. Si es cierto que el yo siempre está situado², no es menos cierto que esa situación es móvil, y que de lo que se trata es de

1 Al que el pensador francés dedicó un escrito hoy perdido.

2 Y esto es lo que con razón ha subrayado la tradición hermenéutica frente a la comprensión desvinculada del mismo a la que propende la epistemología. 
que, a la postre, esa movilidad sea más el resultado de una decisión basada en una liberación autoconsciente de prejuicios ${ }^{3}$, que de la mera inercia. La trascendencia de Beauvoir, la emancipación de las mujeres, siempre tendrá en este sentido algo del gesto cartesiano que, en el fondo, es el gesto que abre la ilustración ${ }^{4}$.

Pero sigamos con el triple movimiento que siguiendo a Lonzi hemos cifrado como la clave para conquistar la identidad: autoconciencia, deseo de ser libre y voluntad de existir. He subrayado la importancia de la duda para lograr la autoconciencia, del gesto de pararse y emprender un camino (no es otra cosa lo que significa la palabra método). En ambas películas hay un paralelismo sorprendente en la primera secuencia, las dos historias comienzan con dos mujeres que cogen un autobús, llevando consigo a sus respectivos hijos. Pilar sale huyendo de su casa, se lleva a Juan, su hijo, el viaje no va ser espacialmente hablando muy largo, sólo se desplaza desde una parte a otra de Toledo buscando refugio en casa de su hermana. Ángela coge un autobús con Guille, su hijo, para regresar a la ciudad de su infancia donde recién ha fallecido su padre, este desplazamiento es un poco mayor, probablemente de Vigo a Madrid.

Estos desplazamientos sin apenas relevancia espacial, son sin embargo el inicio de un largo viaje interior para ambas mujeres. Si se me permite cierta ironía con el título del libro de Taylor, diré que Pilar y Ángela deben remontarse a las fuentes del yo, de su yo. Un viaje desde una existencia sometida y violentada (en el caso de Pilar), o desde la pasividad y una posición subalterna (en el de Ángela) hacia la voluntad de existir. Es aquí donde podemos volver a mirar a otras dos posiciones abstractas sobre la identidad personal para calibrarlas; me refiero a la tradición Lockeana y a las teorías narrativas, que creo pueden complementarse. ¿Cuáles son las condiciones de posibilidad de ese "viaje interior"?

Al final de "Te doy mis ojos" Pilar confiesa a su hermana, cuando esta le dice que no sabe si ha sabido ayudarle, "No sé quién soy. No podía verme". El sentido metafórico del título "Te doy mis ojos" es revelador. ¿A quién da sus ojos Pilar? En una escena erótica de la película Antonio le pide un regalo a Pilar; en un gesto de ternura, Pilar le dice que le da sus ojos. Al darle sus ojos a Antonio, le ha dado la capacidad de percibir y examinar la realidad por sí misma, ha renunciado al control de su propia vida. Las causas de esta renuncia podrían ser una combinación explosiva: el amor que Pilar siente por Antonio, su marido y maltratador, y el miedo que siente a perderlo, pues la dominación es tal que Pilar cree que sin Antonio no es nada. La dialéctica del amo y el esclavo está servida.

Pero el espectador, a quien Pilar también ha dado sus ojos para que sea testigo de su viaje interior, sabe que en ese momento de la película en que Pilar dice "no sé quién soy" también ha empezado a verse y actuar por sí misma. El proceso ha sido tremendamente duro y la condición necesaria para lograr esa identidad, podríamos decir con los teóricos narrativos, ha sido la posibilidad de distanciarse de sí misma y narrarse, ser consciente de su biografía, una historia que se despliega en el tiempo y que permite trazar las conexiones de vida suficientes para entretejer pasado, presente y provenir.

3 Y de estos es de los que Descartes quería que la fillosofía ayudara a librarnos. Para él, recuérdese, los prejuicios eran la primera fuente del error.

4 Quizás por ello Descartes es el principal objetivo crítico del Gadamer de Verdad y método. 
¿Cómo narrarnos a nosotros mismos? ¿Cuál es la facultad privilegiada para lograr el autoconocimiento? En tanto que la narración implica retrospectiva, la memoria, como diría Locke, es clave; pero esta no puede entenderse exclusivamente como la facultad que me permite reconocerme como el sujeto que persiste a través de mis vivencias, sino también como la facultad que me permite interpretarme. Y es aquí donde cabría objetar a la tradición lockeana su concepción individual, prácticamente solipsista, de la memoria. Pues la memoria que permite interpretarme no puede ser el simple reconocimiento de la huella que han dejado en mi ciertos hechos, situaciones y circunstancias sino mi posibilidad de recrearlos, contrastarlos, corregirlos y actuar desde ese nuevo relato. Y es en esa interpretación en la que va a ser clave el papel de los otros ("La categoría de Otro es tan esencial como la conciencia misma", Beauvoir, 2005, 55), las otras voces que dialogan conmigo y que se posicionan a propósito de mi actuar, pues el relato que los otros me ofrecen será la piedra de toque que me permita obtener una imagen más ajustada de mí misma, ya que, aunque sea simplemente por coherencia, me permitirá combatir el autoengaño, la justificación o el olvido como mecanismos de defensa. En suma, que la autoconciencia es de alguna manera la interiorización de los otros. Pero cuidado, no pensemos en un proceso limpio, aséptico, exento de distorsiones y conflictos, como propenden a presentar este proceso tantos y tantos teóricos narrativos - Taylor sería un caso paradigmático-.

Volviendo para terminar a las películas, había comentado apelando a la expresión de Taylor como ambos films tienen algo de road movie, quizás mas bien de bildungsroman, en cuanto que hay un viaje interior hacia las fuentes del yo. El paisaje que transita ese yo está poblado por los otros. No cualquier otro sino el otro significativo, las personas a las que más íntima y emocionalmente estamos vinculados. Personas con las que para ser realistas hay que reconocer que se establecen relaciones de poder y a veces sumisión. El periplo de la conciencia de Pilar y Ángela va a pasar por sucesivas enajenaciones y reconciliaciones mediadas por las discusiones que entablan con aquellos a los que se vinculan ${ }^{5}$. Es en este enfrentarse a los otros que se consigue forjar una nueva identidad; un enfrentarse a los otros que en su forma más radical pasa por desprenderse de ese otro-significativo que oprime, la figura del padre en el caso de Ángela o del marido en el caso de Pilar.

Concluyo, lo que nos ha permitido el relato de la vida particular de estas dos mujeres protagonistas de las dos películas analizadas es plantear algunas enmiendas a las concepciones más abstractas de la identidad personal. En relación al cartesianismo y la tradición lockeana denunciar el carácter solipsista tanto de la autoconciencia cuanto de la memoria como capacidades privilegiadas de la identidad personal que en estas teorías subyacen. Lo que objetaríamos a las teorías narrativas es su ecumenismo, su creencia un poco ingenua o nada dialéctica del papel del diálogo en esa recreación de nuestra vida que constituye nuestra identidad. Por último, subrayar que la conquista de la identidad de cualquier ser humano en particular y de cualquier mujer, también en particular, siempre se da en un contexto social y entre los otros que lo pueblan, un contexto conflictivo o cuanto menos tenso. Homenajeando a Simon de Beauvoir, Ángela y Pilar han llegado a ser las mujeres que serán.

5 Podría repasar algunas secuencias en las que las protagonistas se enfrentan con las personas más significativas, que como un espejo les devuelven una imagen de sí mismas en las que quizás no habían reparado. 


\section{Referencias}

Benhabid, S. (1995-96): "Fuentes de la identidad y del yo en la teoría feminista contemporánea”, Laguna, Revista de Filosofía, no 3 .

Beauvoir, S. (2005): El segundo sexo, Madrid, Cátedra.

Lonzi, C. (2004): Librería de mujeres de Milán. No creas tener derechos: la generación de la libertad femenina en las ideas y vivencias de un grupo de mujeres, Madrid, Horas y Horas.

Najera, E. (1999): “Feminismo y narración”, Thémata, no 22.

Taylor, CH. (1996): Las fuentes del yo, Barcelona, Paidós. 